\title{
COMPARATIVE EVALUATION OF ACAMPROSATE WITH OTHER DRUGS IN CENTRAL TINNITUS
}

Sharanjit Kaur, Harinder jot Singh, Naresh Jyoti

1. Assistant Professor. Department of Pharmacology, CMCH, Pathankot.

2. Assistant Professor. Department of Physiology, $\mathrm{CMCH}$, Pathankot.

3. Assistant Professor. Department of Pharmacology, $\mathrm{CMCH}$, Pathankot.

\section{CORRESPONDING AUTHOR:}

Dr. Sharanjit Kaur,

H. No. 39-A Rattan Nagar,

Tripuri Town Patiala,

E-mail: drsharan25@gmail.com

Ph: 00919781327788

ABSTRACT: AIM: To compare the efficacy of acamprosate with other drugs to decrease the severity of sensorineural tinnitus. MATERIAL AND METHOD: The study was randomised double-blind, placebo controlled, crossover. Forty adult subjects ( $>18$ years of age), of either sex with tinnitus of sensorineural origin, were administered either acamprosate $333 \mathrm{mg}$ tds or matched placebo for a period of six weeks followed by a washout period of one week. Drug therapy was switched for another six weeks in consonance with the crossover design. The effect of acamprosate and placebo on subjective relief and objective improvement was evaluated by using modified tinnitus severity quality of life scores and audiometry with tinnitus matching in frequency and loudness. RESULTS: At the end of study the drug had shown a statistically significant improvement in reducing the tinnitus score in $92.5 \%$ of the patients and placebo with an improvement in $12.5 \%$ of the patients in contrast to other drugs belonging to this group.

CONCLUSION: Acamprosate is an effective drug in treating the severity of sensorineural tinnitus

KEYWORDS: Sensorineural tinnitus, tinnitus matching, acamprosate

INTRODUCTION: Tinnitus is characterized by the perception of sound or noise in the absence of any internal or external acoustical stimulation. ${ }^{1}$ Increase in the release of Glutamate; the major neurotransmitter both in the cochlea and in the central auditory pathways; has been suggested to be involved in the generation and maintenance of sensorineural tinnitus by causing "excitotoxicity". ${ }^{2}$ In recent years therapy for tinnitus has focused on drugs that act directly on CNS neurotransmitters, like glutamate, GABA, serotonin, acetylcholine and dopamine. Glutamate receptor antagonists which block glutamate binding sites and prevent/attenuate the influx of calcium can be useful for the condition. ${ }^{3}$ Acamprosate which acts by a dual mechanism of action, both as a glutamate antagonist and as a GABA agonist reported a relief of tinnitus in over $80 \%$ of patients in a double blind study. ${ }^{4}$

AIMS AND OBJECTIVES: To compare the efficacy of acamprosate with other drugs to decrease the severity of sensorineural tinnitus.

MATERIAL AND METHOD: The protocol for study was submitted to the Institutional Ethics Committee (IEC) and approval was sought. After getting approval from concerned authorities, 40 subjects were included in the present study. 
SUBJECTS: Forty adult subjects ( $>18$ years of age), of either sex and suffering from unilateral, bilateral or generalized tinnitus of sensorineural origin, presenting at the Outpatient Department of Ram Lal Eye and Ear, Nose and Throat Hospital and volunteering to participate, were included in this study.

Informed consent was taken from the patient after giving all the aspects of the study.

Type of study: Prospective, randomized, placebo controlled, double-blind, cross over design.

A complete medical history and general physical examination was recorded on a prescribed Performa from all the patients.

Following tuning fork tests were performed to make a preliminary assessment of type and amount of hearing loss:

- $\quad$ Rinne's Test using tuning forks of 256, 512 and $1024 \mathrm{~Hz}$.

- Weber's Test using tuning forks of $512 \mathrm{~Hz}$.

- Absolute Bone conduction test using tuning fork of $512 \mathrm{~Hz}^{5}$

All the patients were then subjected to Pure Tone Audiometry and tinnitus matching in terms of frequency and loudness using AAA222 Inter-acoustic Audiometer.6

A validated questionnaire was used and filled by assisting the patient to quantify the impact of subjective sensation of tinnitus on patient's 'Quality of Life' (QOL).7 The scoring system was done to quantify the severity of tinnitus and its impact on quality of life. These patients were also subjected to visual analogue scale for loudness in cm along a $10 \mathrm{~cm}$ scale. 8

These patients were provided with acamprosate $333 \mathrm{mg}$ tds or matched placebo for a period of fifteen days. They were instructed to maintain a diary to keep a record of medication intake and any significant events. They were instructed to come back to the ENT OPD every fifteen days to fill in the questionnaire, had their ENT examination and then received an additional fifteen day supply. This procedure repeated every fifteen days for the duration of the study. Group I: tab. acamprosate 333mg 1 tab. P.O. thrice a day

Group II: matched placebo 1 tab. P.O. thrice a day

This schedule of treatment was continued for forty five days. Afterwards these patients were subjected to a washout period of seven days and later crossed over to acamprosate or placebo as follows for next forty five days.

Group I: matched placebo 1 tab. P.O. thrice a day

Group II: tab. acamprosate 333mg 1 tab. P.O. thrice a day

The effect of the drug was studied both as a subjective and objective improvement in Visual Analogue Score (VAS) or QOL questionnaire score. A decrease in tinnitus loudness was considered as objective improvement. The results were then compiled and analysed statistically by using student ' $\mathrm{t}$ ' test for independent samples.

The criterion for determination of significance will be at $5 \%$, with ' $p$ ' value of the statistical test smaller or equal to 0.05 .

RESULTS: A total of forty five patients were taken. Two patients reported their conditions to be worse and they were shifted to another treatment. Three patients were lost during the study. Forty patients were able to complete the study. All of them had sensorineural hearing loss downward curve. In $65 \%$ of patients was bilateral hearing loss; in $35 \%$ of them had bilateral tinnitus.

The age of patients was 18 to 84 years with an average of 53 years. 
The improvement score or reduction in tinnitus score was observed in $92.5 \%$ of patients included in this study as compared to previous study which showed an improvement score of $86.9 \%$ in 90 days. At the end of study only five patients (7.5\%) showed no improvement as compared to $13.06 \%$ in previous study. Twenty-one patients $(77.5 \%)$ reported improvement below $50 \%$, six patients (15\%) reported improvement higher than $50 \%$. Five patients $(12.5 \%)$ reported that their tinnitus had disappeared as compared to $13.04 \%$ in previous study as shown in table I.

TABLE I: SUBJECTIVE IMPROVEMENT

\begin{tabular}{|l|l|l|}
\hline Improvement score & During drug treatment & During placebo treatment \\
\hline No improvement & 3 & 0 \\
\hline $0-25 \%$ & 10 & 5 \\
\hline $26-50 \%$ & 21 & 0 \\
\hline $51-75 \%$ & 1 & 0 \\
\hline $76-100 \%$ & 5 & 0 \\
\hline
\end{tabular}

Table II: OBJECTIVE IMPROVEMENT

\begin{tabular}{|l|l|l|}
\hline Improvement score & During drug treatment & During placebo treatment \\
\hline No improvement & 8 & 0 \\
\hline Decrease in tinnitus loudness & 32 & 0 \\
\hline
\end{tabular}

To assess the progression of tinnitus throughout study time, we had performed the statistical analysis of each study group at first day, $45^{\text {th }}$ day, $52^{\text {nd }}$ day and $97^{\text {th }}$ day in terms of VAS score and QOL questionnaires as shown in table III, IV, V.

TABLE III: VISUAL ANALOGUE SCALE SCORE FOR LOUDNESS OF TINNITUS

\begin{tabular}{|l|l|l|l|l|}
\hline VAS & $\mathbf{1}^{\text {st }}$ day & $\mathbf{4 5}^{\text {th }}$ day & $\mathbf{5 2}^{\text {nd }}$ day & $\mathbf{9 7}^{\text {th }}$ day \\
\hline Group I & $7.1 \pm 1.17$ & $4.2 \pm 1.95$ & $4.15 \pm 1.95$ & $4.05 \pm 1.98$ \\
\hline Group II & $6.45 \pm 1.5$ & $6.3 \pm 1.42$ & $6.3 \pm 1.42$ & $4.25 \pm 1.7$ \\
\hline
\end{tabular}

TABLE IV: QUALITY OF LIFE SCORE FOR FREQUENCY STATEMENT

\begin{tabular}{|l|l|l|l|l|}
\hline Group & $\mathbf{1}^{\text {st }}$ day & $\mathbf{4 5}^{\text {th }}$ day & $\mathbf{5 2}^{\text {nd }}$ day & $\mathbf{9 7}^{\text {th }}$ day \\
\hline I & $66.5 \pm 15.4$ & $38.8 \pm 21.5$ & $38.8 \pm 21.5$ & $36.65 \pm 21.5$ \\
\hline II & $59.57 \pm 16.4$ & $59.4 \pm 16.3$ & $59.4 \pm 16.3$ & $48.5 \pm 7.5$ \\
\hline
\end{tabular}

TABLE V: QUALITY OF LIFE SCORE FOR SEVERITY STATEMENT

\begin{tabular}{|l|l|l|l|l|}
\hline Group & $\mathbf{1}^{\text {st }}$ day & $\mathbf{4 5}^{\text {th }}$ day & $\mathbf{5 2}^{\text {nd }}$ day & $\mathbf{9 7}^{\text {th }}$ day \\
\hline I & $68.73 \pm 18.7$ & $42.33 \pm 24.8$ & $42.33 \pm 24.8$ & $42.21 \pm 24.9$ \\
\hline II & $67.37 \pm 19.7$ & $67.19 \pm 19.5$ & $67.19 \pm 19.5$ & $48.8 \pm 22.37$ \\
\hline
\end{tabular}

This improvement was also assessed objectively by psychoacoustic reduction in tinnitus matching. $20 \%$ did not show any improvement while $80 \%$ patients showed improvement in tinnitus loudness. The decrease in tinnitus loudness was varied from $5 \mathrm{db}$ to zero as shown in table VI. 
TABLE VI: TINNITUS MATCHING FOR LOUDNESS IN DB

\begin{tabular}{|l|l|l|l|l|}
\hline Group & $1^{\text {st }}$ day & $\mathbf{4 5}^{\text {th }}$ day & $\mathbf{5 2}^{\text {nd }}$ day & $\mathbf{9 7}^{\text {th }}$ day \\
\hline I & $50.5 \pm 20.5$ & $43 . \pm 23.9$ & $43 . \pm 23.9$ & $43 . \pm 23.9$ \\
\hline II & $49 \pm 20.17$ & $49 \pm 20.17$ & $49 \pm 20.17$ & $40.5 \pm 24.05$ \\
\hline
\end{tabular}

In placebo group, $12.5 \%$ reported improvement subjectively only as shown in table I and II.

Thus at the end of study, the drug had shown a statistically significant improvement in reducing the tinnitus score in $92.5 \%$ of the patients and placebo shown a little improvement in $12.5 \%$ of the patients. The subjective improvement was greater than objective improvement. The drug was well tolerated and did not show any serious drug reactions. No patient had any change in audiogram shape. Those patients who were fully treated or obtained the best results were those who had the symptoms for less time.

The subjective improvement was greater than objective improvement. The drug was well tolerated and did not show any serious drug reactions.

DISCUSSION: Tinnitus is defined as a phantom auditory perception-it is a perception of sound without corresponding acoustic or mechanical correlates in the cochlea. ${ }^{9}$ Tinnitus is a subjective phenomenon that is difficult to evaluate objectively, with it being measured, quantified, and described only based on the responses of patients. ${ }^{10}$

It has been established that, that $35-40 \%$ of all adults over 17 years of age experience temporary or noises lasting longer than 5 minutes of various degrees of loudness at some time. A miniscule number of patients $(0.5 \%)$ are in urgent need of treatment. These patients may also experience sleep disorders, poor concentration and depression leading to a vicious cycle from which there seems no escape. Another, $0.5-1 \%$ of adults report tinnitus of such severity so as to have a significant adverse effect on their quality of life. ${ }^{11}$

Current treatments of tinnitus are not cures; they are a means to reduce tinnitus perception or awareness. Well controlled trials of management strategies are few and published success rates of most treatments remain controversial. Despite this there is sufficient evidence to advocate existing strategies to reduce tinnitus annoyance and improve quality of life.

Alll drugs investigated in this work are related to different groups with no specific action to decrease the severity of tinnitus. We are still left with undefined drugs. Considering such situation, any new perspective seems to be received as a novel alternative. ${ }^{12}$

The introduction and application of new drug therapies have increased the success of tinnitus treatment. Many of the drug treatments that were aimed at level of the cochlea, e.g. using intratympanic injections of gentamicin, dexamethasone or lidocaine or the CNS using systemic delivery. Drugs like lidocaine have been shown to temporarily eliminate ear noise, but have to be given intravenously and in doses so high that serious side effects are reported too often.13

The use of antidepressants as a potential tinnitus treatment was initially very promising but has shown disappointing results on long term use. This has been primarily because of the complexity of the central nervous system, and the multifactorial causes of tinnitus. ${ }^{14}$ 
Other drugs already studied for treatment of tinnitus are baclofen (improvement in about 9.7\%), ${ }^{15}$ caroverine $(63.3 \%),{ }^{16}$ nimodipine (16.13\%), ${ }^{17}$ clonazepam $(32 \%){ }^{18}$ and trimetazidine (89\%). ${ }^{19}$

Different studies have shown that sensorineural tinnitus is caused by an imbalance of two neurotransmitters Glutamate and GABA in the auditory pathway. ${ }^{20}$ The ability to modulate the action of neurotransmitters in afferent auditory pathway opens new possibilities in the therapy of this symptom

Drugs affecting the GABA levels may show improvement in reducing the severity of tinnitus. Alprazolam in a double-blind, placebo-controlled study, reduced tinnitus loudness in $65 \%$ of subjects compared to $5 \%$ in the control group. Clonazepam, a long acting benzodiazepine significantly reduced tinnitus loudness (32\%) and annoyance relative to the control group. ${ }^{21}$ Vigabatrin and tiagabine two drugs that act on different aspects of GABAergic neurotransmission, have been studied in an animal model of noise-induced tinnitus. ${ }^{22}$ Clinical use of benzodiazepine is limited by their side effects such as high risk of drug dependency and personality changes. ${ }^{23}$

Gabapentin a GABA-mimetic has shown encouraging results in the improvement of tinnitus in high doses. But there is little evidence to support a general use of gabapentin in subjective tinnitus. ${ }^{24}$

Modulation of glutaminergic transmission by topical administration of the nonselective glutamate receptor antagonist caroverine to the inner ear has been proposed for tinnitus treatment. In a single-blind study subjects tinnitus loudness and tinnitus matching were measured before and after treatment and at 1 week post-treatment. Immediately posttreatment, $63 \%$ of the caroverine group and $43 \%$ of the placebo group showed a significant response. However, the systemic use of nonselective glutamate receptor blockers such as caroverine is limited by severe neurological and psychiatric side effects. ${ }^{16}$

Memantine another NMDA receptor antagonist was used to evaluate its efficacy in tinnitus during a placebo controlled cross over study. But the results were not upto the mark to show its efficacy. It might be due to wrong dosage administered for inadequate period of time. ${ }^{25}$ Acamprosate in another clinical trial $87 \%$ of the subjects in the acamprosate group showed improvement of $87 \%$ of the subjects taking acamprosate including three subjects in whom tinnitus disappeared, compared to $44 \%$ in the placebo group. ${ }^{4}$ (Table VII and GRAPH I)

Like memantine, neramexane acts as a noncompetitive, voltage-dependent NMDA antagonist. It also blocks $\alpha 9$ and $\alpha 10$ nicotinic cholinergic receptors which are expressed on inner hair cells in the inner ear. In one large clinical trial this compound has shown a positive improvement in tinnitus handicap score as compared to placebo group. ${ }^{26}$

TABLE VII: \%AGE OF PATEINTS SHOWING IMPROVEMENT IN TINNITUS LOUDNESS

\begin{tabular}{|l|l|l|l|}
\hline Drugs modulating GABA neurotransmission & Alprazolam & Clonazepam & Gabapentine \\
\hline $\begin{array}{l}\text { \%age of patients showing improvement in } \\
\text { tinnitus loudness }\end{array}$ & $65 \%$ & $32 \%$ & $59 \%$ \\
\hline Drugs modulating GABA neurotransmission & Caroverine & Memantine & Acamprosate \\
\hline $\begin{array}{l}\text { \%age of patients showing improvement in } \\
\text { tinnitus loudness }\end{array}$ & $63 \%$ & $37.2 \%$ & $87 \%$ \\
\hline
\end{tabular}


CONCLUSION: The most accepted theory of glutamate neurotoxicity and benzodiazepine deficiency which is based on the receptor targeted therapy are responsible for the possible cause of the tinnitus of sensorineural in origin.

The rationale of treating tinnitus is based on modulation of these neurotransmitters in afferent auditory pathway by reducing the cytotoxicity and maintaining the cochlear homeostasis

There are only a few drugs that act specifically on the GABA-glutamate without showing any major undesirable side effects.

The drugs which affect the GABA levels are benzodiazepines and local anaesthetics like lidocaine. But these drugs they show the site specificity and pharmacokinetic specificity, high risk of drug dependency and personality changes.

The drugs affecting the NMDA receptors are the new promising candidates for the treatment of central type tinnitus.

The acamprosate drug which acts through dual mechanism of increasing the GABA expression and decreasing the glutamate expression, work specifically on subgroup of tinnitus patients.

Further in future ongiong clinical trials with appropriate size and sample may help to revolutionize the treatment of tinnitus.

\section{BIBLIOGRAPHY:}

1. Roedel KL. The Ear Foundation of Arizona Information About Tinnitus: General Information and Prevalence. [serial Online]. 1992 [cited 2008 Aug 21]; [12 screens]. Available from: URL:http://www.ata.org/

2. Pujola R and Puel JC. Excitotoxicity, Synaptic Repair, and Functional Recovery in the Mammalian Cochlea: A Review of Recent Findings. Annals New York Academy of Sciences. 2002;55:249-55.

3. Gillespie DC, Kim G, Kndler K. Inhibitory synapses in the developing auditory system are glutaminergic. Nature neuroscience. 2005 January 30;55(5):332-38

4. Azevedo, A. A. and Figueiredo, R. R. Tinnitus treatment with acamprosate: double-blind study. Rev Bras Otorrinolaringol. (Engl Ed) 2005;71:618-623.

5. Chartrand MS. Indiana Jones \& the Lost of Art of Tuning Fork Testing The Hearing Journal [serial online]. 2007 [cited 2008 Oct 16]; Avaiable from: URL:http://www.Audiology Online.com $2007 / \mathrm{html}$.

6. Lovrinic JH. Pure Tone and Speech Audiometry. In: Keith RW, editor. Audiology for the Physician. Baltimore: Williams \& Wilkins; 1980.p. 13-31.

7. Folmer RL, Griest SE. Chronic tinnitus resulting from head or neck injuries. The Laryngoscope. 2003;113:821-27.

8. Azevedo AA, Oliveira PM, Siqueira AG and Figueiredo RR. A critical analysis of tinnitus measuring methods. Revista brasileira de otorrinolaringologia (English ed ). 2007;73:418-423.

9. Jastreboff PJ. Phantom auditory perception (tinnitus): Mechanisms of generation and perception. Neuroscience Research. 1990;8:221-54.

10. Han IB, Lee HW, Kim TY, Lim JS, Shin KS. Tinnitus: Characteristics, Causes, Mechanisms, and Treatments. J Clin Neurol 2009;5:11-19.

11. Heller AJ. Classification and epidemiology of tinnitus. Otolaryngology Clinics of North America. 2003;36:239-48. 
12. Salvi, R., Lobarinas, E., Sun, W. Pharmacological treatments for tinnitus: New and old. Drugs of the Future. 2009;34(5):381.

13. Tayyar Kalcioglu M, Bayindir T, Erdem T, Ozturan 0. Objective evaluation of the effects of intravenous lidocaine on tinnitus. Hear Res. 2005 Jan;199(1-2):81-8.

14. Robinson S, Viirre E, Stein M. Antidepressant therapy in tinnitus. Hearing research.2007;226:221-231.

15. Westerberg BD, Roberson JB, Stach BA. A double-blind placebo controlled trial of baclofen in the treatment of tinnitus. Am J Otol. 1996 Nov;17(6):896-903.

16. Domeisen, H., Hotz, M. A. and Hausler, R. Caroverine in tinnitus treatment. Acta Otolaryngol. 1998;118:606- 608.

17. Davies E, Knox E, Donaldson I. The usefulness of nimodipine, an L-calcium channel antagonist, in the treatment of tinnitus. Br J Audiol. 1994 Jun;28(3):125-9.

18. Pech A. A multicenter double blind versus placebos study of trimetazidine in tinnitus. A clinical approach to tinnitus. Ann Otolaryngol Chir Cervicofac. 1990;107 Suppl 1:66-7.

19. Ganança MM, Caovilla HH, Ganança FF, Ganança CF, Munhoz MSL, Da Silva ML, Serafini F. Clonazepam in the pharmacologic treatment of vertigo and tinnitus. Int Tinnitus J. 2002;8(1):50-3.

20. Shulman A, Goldstein B. A Final Common Pathway for Tinnitus- Implications for Treatment. Int Tinnitus J. 1996;2:137-14

21. Bahmad FM Jr, Venosa AR, Oliveira CA. Benzodiazepines and GABAergics in treating severe disabling tinnitus of predominantly cochlear origin. Int Tinnitus J 2006;12(2):140-4. [PubMed:17260879]

22. Brozoski TJ, Spires TJ, Bauer CA. Vigabatrin, a GABA transaminase inhibitor, reversibly eliminates tinnitus in an animal model. J Assoc Res Otolaryngol 2007 Mar;8(1):105-18.

23. Busto U, Fornazzari L, Naranjo CA. Protracted tinnitus after discontinuation of long-term therapeutic use of benzodiazepines. J Clin Psychopharmacol 1988 Oct;8(5):359-62.

24. Bakhshaee M, Ghasemi M, Azarpazhooh M et al. Gabapentin effectiveness on the sensation of subjective idiopathic tinnitus: a pilot study. European archives of oto-rhinolaryngology. 2007;166:287-301.

25. Figueiredo RR, Langguth B, de Oliveira PM, de Azevedo AA. Tinnitus treatment with memantine. Otolaryngol Head Neck Surg 2008 Apr;138(4):492-6.

26. Suckfüll M, Althaus M, Ellers-Lenz B. A randomized, double-blind, placebo-controlled clinical trial to evaluate the efficacy and safety of neramexane in patients with moderate to severe subjective tinnitusBMC Ear, Nose and Throat Disorders 2011, 11:1 


\section{ORIGINAL ARTICLE}

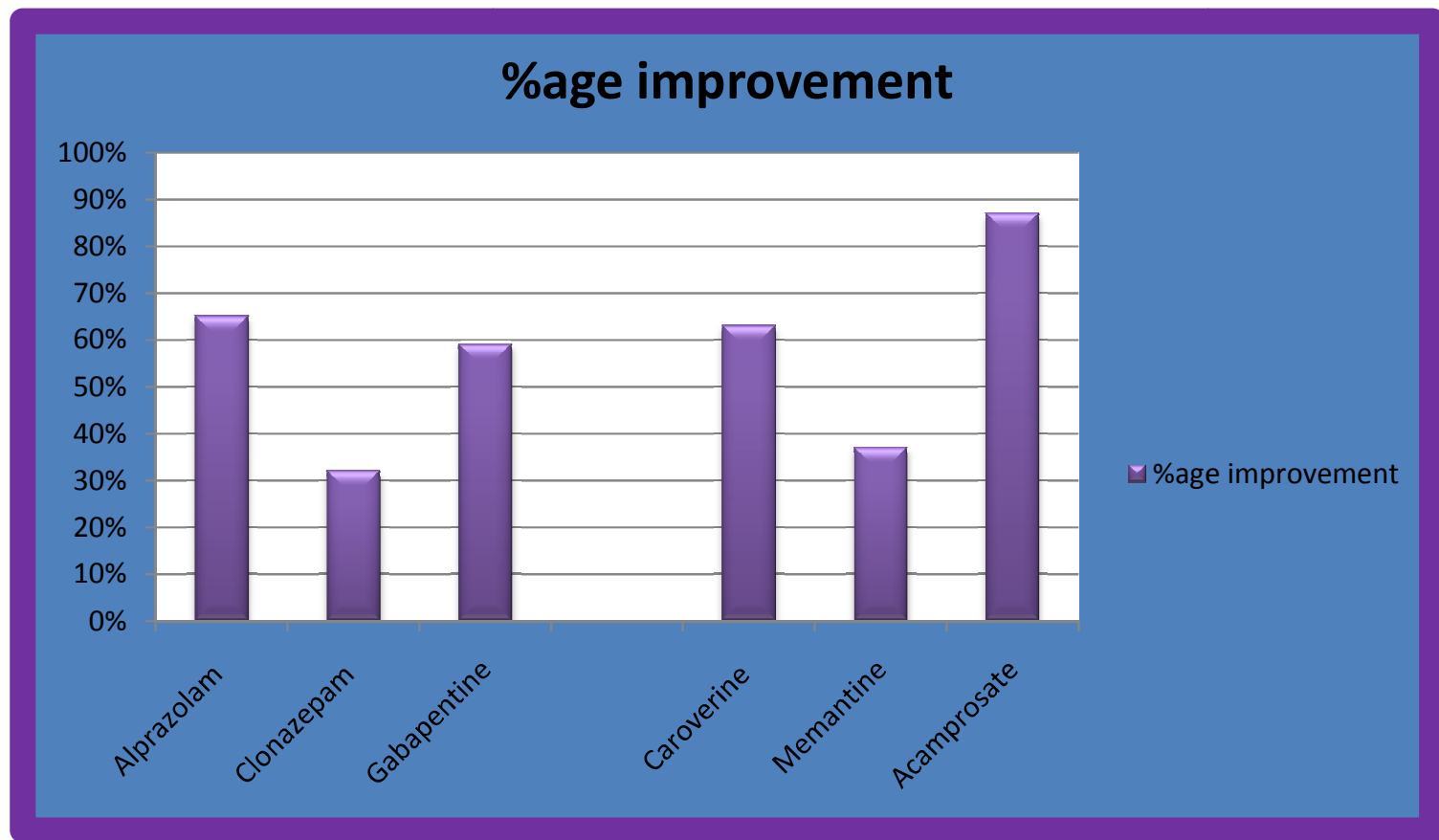

GRAPH I: \%AGE OF PATEINTS SHOWING IMPROVEMENT IN TINNITUS LOUDNESS 